\title{
The major secreted protein Msp1/p75 is O-glycosylated in Lactobacillus rhamnosus GG
}

\author{
Sarah Lebeer ${ }^{1,2^{*}+}$, Ingmar JJ Claes ${ }^{1 \dagger}$, Crina IA Balog ${ }^{3}$, Geert Schoofs ${ }^{1}$, Tine LA Verhoeven ${ }^{1}$, Kris Nys ${ }^{4}$, \\ Ingemar von Ossowski ${ }^{5}$, Willem M de Vos ${ }^{5}$, Hanne LP Tytgat ${ }^{1,2}$, Patrizia Agostinis ${ }^{4}$, Airi Palva ${ }^{5}$, Els JM Van Damme ${ }^{6}$, \\ André M Deelder ${ }^{3}$, Sigrid CJ De Keersmaecker ${ }^{1}$, Manfred Wuhrer ${ }^{3}$ and Jos Vanderleyden ${ }^{1}$
}

\begin{abstract}
Background: Although the occurrence, biosynthesis and possible functions of glycoproteins are increasingly documented for pathogens, glycoproteins are not yet widely described in probiotic bacteria. Nevertheless, knowledge of protein glycosylation holds important potential for better understanding specific glycan-mediated interactions of probiotics and for glycoengineering in food-grade microbes.

Results: Here, we provide evidence that the major secreted protein Msp1/p75 of the probiotic Lactobacillus rhamnosus GG is glycosylated. Msp1 was shown to stain positive with periodic-acid Schiff staining, to be susceptible to chemical deglycosylation, and to bind with the mannose-specific Concanavalin A (ConA) lectin. Recombinant expression in Escherichia coli resulted in a significant reduction in molecular mass, loss of ConA reactivity and increased sensitivity towards pronase $E$ and proteinase K. Mass spectrometry showed that Msp1 is O-glycosylated and identified a glycopeptide TVETPSSA (amino acids 101-108) bearing hexoses presumably linked to the serine residues. Interestingly, these serine residues are not present in the homologous protein of several Lactobacillus casei strains tested, which also did not bind to ConA. The role of the glycan substitutions in known functions of Msp1 was also investigated. Glycosylation did not seem to impact significantly on the peptidoglycan hydrolase activity of Msp1. In addition, the glycan chain appeared not to be required for the activation of Akt signaling in intestinal epithelial cells by Msp1. On the other hand, examination of different cell extracts showed that Msp1 is a glycosylated protein in the supernatant, but not in the cell wall and cytosol fraction, suggesting a link between glycosylation and secretion of this protein.

Conclusions: In this study we have provided the first evidence of protein O-glycosylation in the probiotic $L$ rhamnosus GG. The major secreted protein Msp1 is glycosylated with ConA reactive sugars at the serine residues at 106 and 107. Glycosylation is not required for the peptidoglycan hydrolase activity of Msp1 nor for Akt activation capacity in epithelial cells, but appears to be important for its stability and protection against proteases.
\end{abstract}

Keywords: Probiotic, glycoprotein, bacterial O-glycosylation, Akt signaling, peptidoglycan hydrolase

\section{Background}

The bacterial cell surface mediates many interactions between bacteria and their changing and sometimes harsh environment $[1,2]$. Diverse selective pressures are acting on bacterial cell surface molecules, resulting in various adaptations of their chemical and structural composition. This is especially true for the wide array of

\footnotetext{
* Correspondence: sarah.lebeer@biw.kuleuven.be

+ Contributed equally

'Centre of Microbial and Plant Genetics, K.U.Leuven, Kasteelpark Arenberg

20, box 2460, B-3001 Leuven, Belgium

Full list of author information is available at the end of the article
}

glycans that often can decorate bacterial cell walls and which are collectively called the bacterial glycome [3]. Cell wall components encompassing the bacterial glycome can include lipopolysaccharides in Gram-negative bacteria, glycosylated teichoic acids in Gram-positive bacteria and peptidoglycan, exopolysaccharides, capsular polysaccharides, glycolipids as well as glycoproteins in both types of bacteria. Bacterial protein glycosylation has long been overlooked, however $O$ - and $N$-linked protein glycosylation systems are increasingly being documented among pathogenic bacteria [4-7]. 
Overall interest in studying bacterial glycoproteins has grown steadily during the past decade, with most reports focused on the various surface structures (e.g., flagellae, pili) related to pathogenesis [5]. In contrast, the glycoproteome of beneficial microbes (commensals and probiotics) has been much less documented so far. Nevertheless, knowledge about protein glycosylation in beneficial microbes holds important potential for the development of 'safe' glycoengineering purposes, such as enhancing the stability and pharmacokinetic properties of therapeutic proteins $[8,9]$ and the design of specific immunomodulatory agents since glycans can mediate very specific interactions, especially in microbe-host signaling [10,11]. Probiotic bacteria, such as various lactobacilli and bifidobacteria with documented health-promoting capacities, are among the best candidates for these purposes. Glycosylation of proteins was previously suggested in Lactobacillus acidophilus [12] and Lactobacillus plantarum [2], but without detailed analyses. Owing to its frequent use in clinical trials [13], we study Lactobacillus rhamnosus GG (LGG) and use it as a model probiotic bacterium for genetic and biochemical investigations on the functional importance of the cell surface properties of such beneficial strains. Single molecule force spectroscopy (SMFS) experiments with lectin-functionalized atomic force microscopy tips have suggested the presence of two major types of surface glycans in LGG [14]. The longest and most abundant polysaccharides are galactose-rich, and correspond with the galactose-rich exopolysaccharide (EPS) molecules [15]. The shorter Concanavalin A (ConA)-reactive glycans are yet unknown [14]. In this current study, we identified the Msp1 (or p75) protein of LGG as a ConA-reactive glycoprotein, investigated its glycosylation site(s) and analyzed the functionality of the glycan component of this protein for some of its documented biological activities. This protein, identified previously as a major secreted protein of LGG, has been shown to have anti-apoptotic and growth-promoting effects in intestinal epithelial cells [16]. Recently, we showed that this protein shows peptidoglycan hydrolase activity with D-glutamyl-L-lysyl endopeptidase specificity and is important for daughter cell separation of LGG [17]. In our present study of Msp1, we provide to the best of our knowledge - the first example of an $O$-glycosylated protein in the probiotic LGG.

\section{Results}

\section{Aberrant electrophoretic migration pattern of Msp1}

Msp1, described previously as the p75 protein [16], is present in abundant amounts in the spent culture supernatant of LGG. Interestingly, this protein appears to have an aberrant migration pattern when analyzed by SDSPAGE and is detected with a significantly higher molecular mass $(70-75 \mathrm{kDa})$ (Figure 1A) than the expected mass $(46.8 \mathrm{kDa})$ for a protein with a $\mathrm{N}$-terminal secretion signal (Figure 1B-C). Previously, this protein was named (i.e. p75) based on its size on SDS gels. Because of the apparent inconsistency in molecular mass, we have designated this protein according to its relative abundance as Msp1 (as in the Major secreted protein). While our electrophoretic results are strongly suggestive of post-translational modification, part of the observed discrepancy in molecular mass might also be due to the disproportionately high number of alanine residues ( $23 \%$ content) in the primary structure of this protein (Figure 1C). Alanine has a low SDS-binding capacity and is known for a high helical propensity causing slow gel migration for proteins with high alanine content [18]. However, we found that a msp1 mutant CMPG10200 [17] (Table 1), expressing a truncated form of Msp1 that lacks a 311-residue C-terminal segment encompassing a large proportion of alanines, still migrates with a larger $(\sim 45 \mathrm{kDa})$ (Figure $2 \mathrm{~B}$ ) than expected size (16.4 kDa) (Figure 1C). Contrastingly, the other major secreted protein of LGG (encoded by LGG_00031 ), here renamed as Msp2 but also known previously as p40 [16], has a predicted molecular mass of $39.7 \mathrm{kDa}$ that corresponds well with its observed migration pattern on SDS gels, suggesting that this protein has not undergone major post-translational modifications (Figure 1A).

\section{Msp1 visually stains as a glycosylated protein}

As the first means to identify any potential carbohydrate modifications on Msp1, proteins in the supernatant of spent cultures of LGG were separated by SDS-PAGE and then treated with a stain that specifically reacts with periodate-oxidized carbohydrate groups (Pro-Q ${ }^{\circledR}$ Emerald 488 glycoprotein stain). As shown in Figure 2A, a $\sim 70-\mathrm{kDa}$ stained band was detected and which we consider to be glycosylated Msp1. However, given that this glycoprotein stain might also cross-react with cell wall polysaccharides, a galactose-rich EPS deficient mutant CMPG5351 [15] and another type of cell wall polysaccharide (CW-PS)-deficient mutant CMPG5413 [14] of LGG were included as controls. As indicated by the staining results (Figure 2A), CMPG5351 and CMPG5413 spent culture supernatants both also displayed a similar-sized band $(\sim 70 \mathrm{kDa})$ as wild-type LGG. Msp2 exhibited no staining above the background level, thus further suggesting that this protein is unlikely to be glycosylated (Figure 2A). To confirm the covalent nature of the carbohydrate modification, and so to exclude any possibility that glycan moieties are merely associated with the protein, we treated Msp1 with the chemical deglycosylating agent trifluoromethanesulfonic acid (TFMS) and were able to observe a clear shift in band migration relative to untreated protein on SDS-PAGE (Figure 2B). To provide additional evidence for glycosylated Msp1, we expressed the msp1 gene in a non-glycosylating E. coli host (BL21(DE3)/pLysS) and found that this 


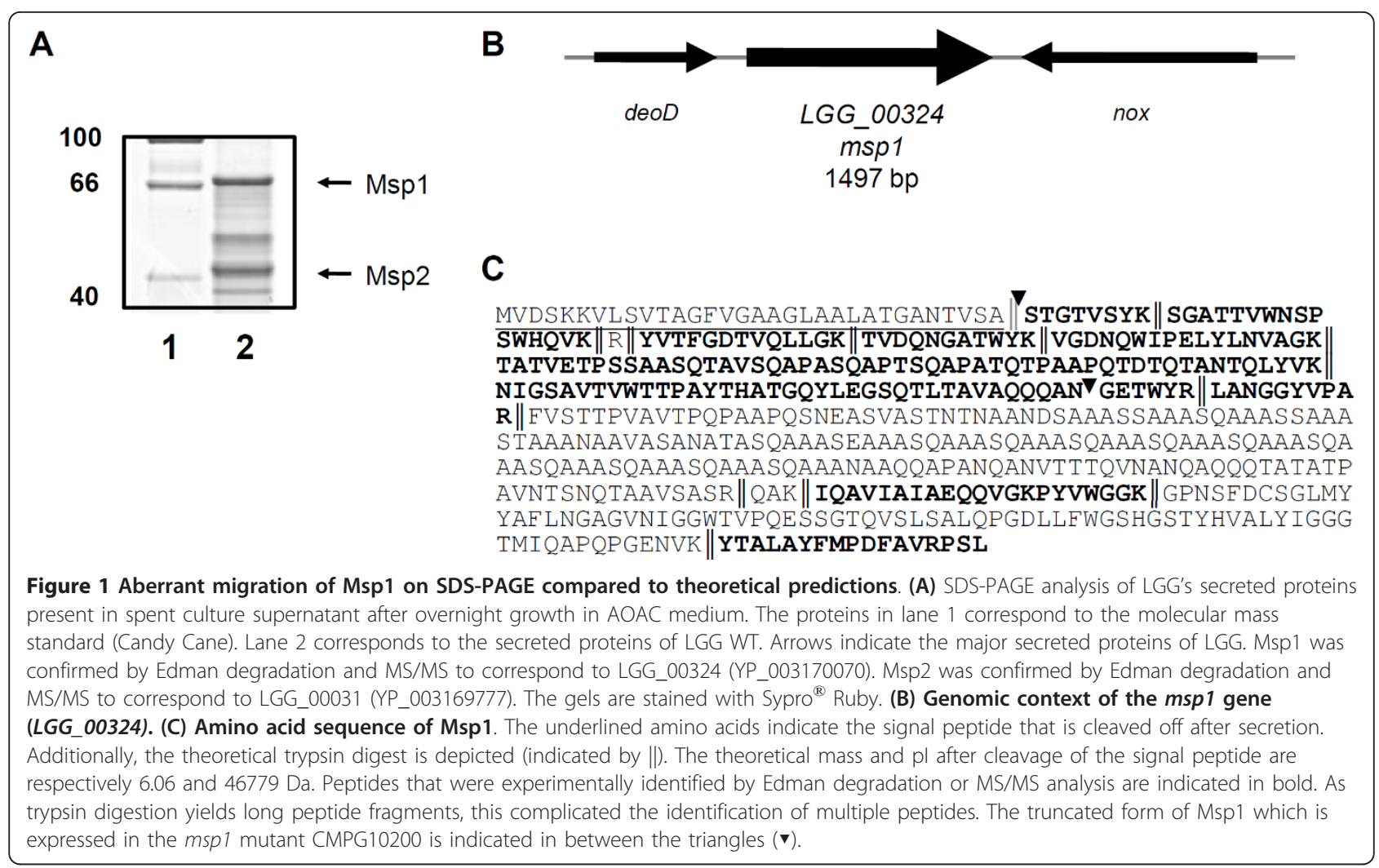

recombinant form is significantly reduced in size when compared to native Msp1 on SDS-PAGE (Figure 2B). Interestingly, several discrete and smaller-sized bands were also associated with the recombinant Msp1 sample and subsequently confirmed to represent truncated Msp1 protein after each band was analyzed by Edman degradation, mass spectrometry (MS) (data not shown), and Western blotting with anti-Msp1 serum (Figure 2B). The presence of these truncated forms suggests that the recombinant-produced Msp1 is less stable, which possibly might be related to the alternate codon usage in $E$. coli. However, given that the non-glycosylated recombinant form appeared to be more sensitive to pronase $\mathrm{E}$ and proteainase $\mathrm{K}$ than native Msp1 (Figure 2C), this is more likely attributed to the Msp1 glycosylated protein being more protease-resistant.

\section{Identification of Msp1 as a ConA-reactive glycoprotein}

To further confirm the glycoprotein nature of Msp1, lectin blotting experiments were carried out. Interestingly, the mannose- and glucose-specific lectin ConA [19] reacted positively with Msp1 (Figure 2B, third panel). Following TFMS treatment or recombinant expression in E. coli BL21(DE3)/pLysS, this reactivity was no longer detected for Msp1. These data were further confirmed by testing other lectins that have overlapping specificities, i.e. GNA from Galanthus nivalis and HHA from Hippeastrum hybrid (data not

Table 1 Lactobacillus strains used in this study

\begin{tabular}{|c|c|c|c|}
\hline Lactobacillus & Strain number & Relevant characteristics & Reference \\
\hline \multirow[t]{4}{*}{ L. rhamnosus GG (LGG) } & ATCC53103 & Human isolate; wild-type (WT) & ATCC \\
\hline & CMPG10200 & Msp1/p75 knock-out mutant, Ery ${ }^{R}$ & [17] \\
\hline & CMPG5413 & Deficient in major cell wall polysaccharides (CW-PS); $T c^{R}$ & {$[29-31]$} \\
\hline & CMPG5351 & welE knock-out mutant; deficient in long-galactose-rich EPS; $T c^{R}$ & {$[15]$} \\
\hline L. rhamnosus & ATCC7469 & Dairy isolate; type strain & BCCM/ATCC \\
\hline L. rhamnosus & GR-1 & Human vaginal isolate & [32]; Chr. Hansen \\
\hline L. casei & ATCC334 & Dairy isolate, type strain & BCCM/ATCC \\
\hline L. casei & ATCC393 & Dairy isolate & BCCM/ATCC \\
\hline L. casei & DN-114001 & Dairy isolate & Danone (Actimel) \\
\hline
\end{tabular}




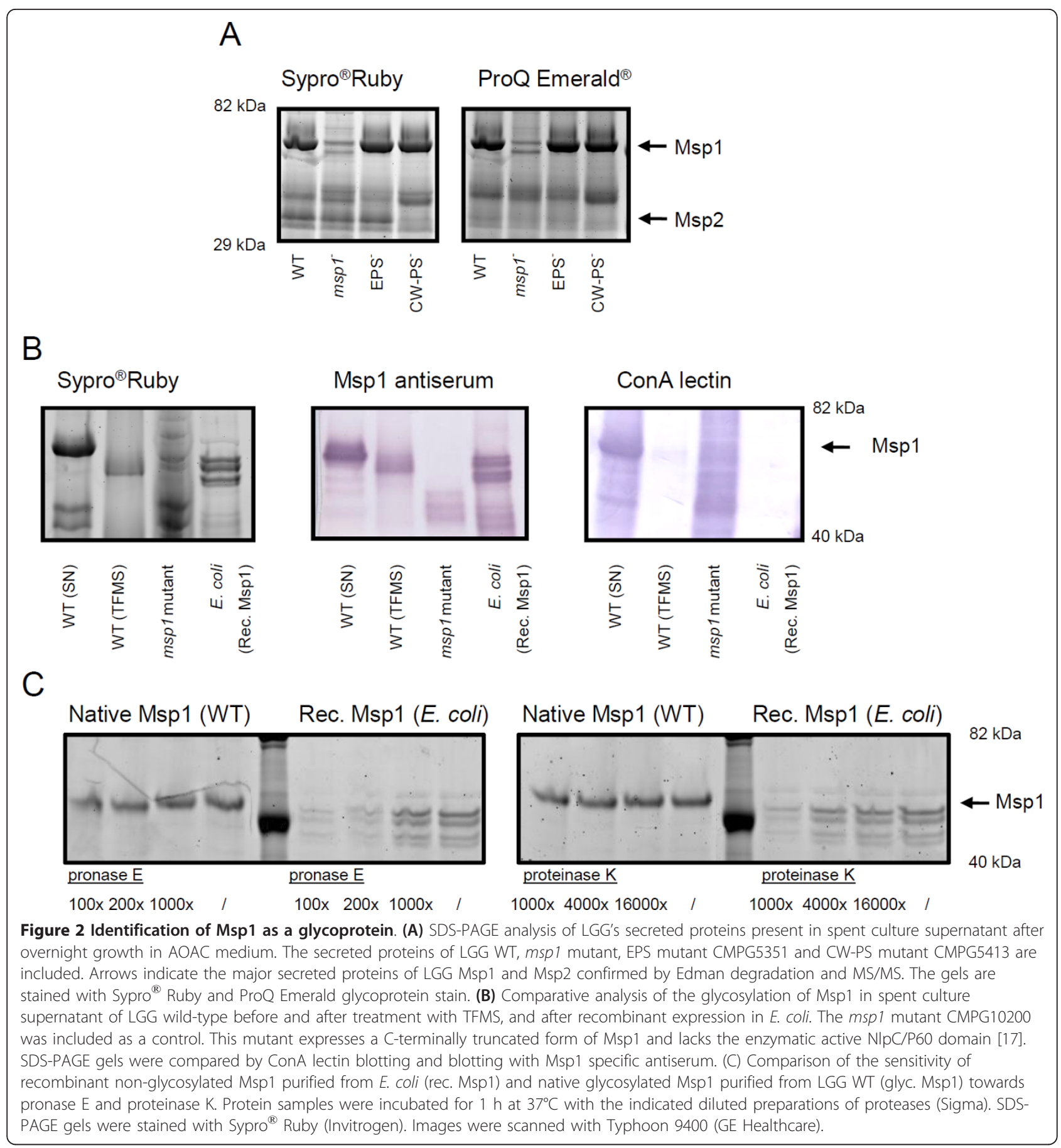

shown). Given that all the above lectins interact with terminal mannose residues [20], other lectins with different specificities, such as fucose (from Ulex europaeus) and sialic acid (MAA from Maackia amurensis and SNA-I from Sambucus nigra), were also used but these failed to react (data not shown). Monosaccharide component analysis confirmed the presence of mannose in this glycoprotein and absence of fucose and sialic acid (data not shown). The C-terminally truncated form of
Msp1 of the CMPG10200 mutant appeared to be still reactive with ConA (Figure $2 \mathrm{~B}$, third panel), suggesting that the ConA-reactive glycosylation site(s) are confined to the $\mathrm{N}$-terminal part.

\section{Msp1 is O-glycosylated at $\mathrm{S}_{106}-\mathrm{S}_{107}$}

Glycosylation of Msp1 was further analyzed by MS of (glyco-)peptides. Gel bands containing Msp1 were subjected to reduction, alkylation, and trypsin treatments 
and the resulting peptides were analyzed by reversed phase-LC-ion trap-MS/MS. Evaluation of fragmentation spectra together with searches of public databases (NCBI) gave partial coverage of the Msp1 protein (gi199599310). Most peptides with sizes larger than $600 \mathrm{Da}$ and smaller than $8000 \mathrm{Da}$ were identified by either database searching or manual interpretation (Table 2). The manual interpretation of the LC-MS/MS data revealed glycopeptide clustering that appears as $[\mathrm{M}+4 \mathrm{H}]^{4+},[\mathrm{M}+5 \mathrm{H}]^{5+}$, and $[\mathrm{M}+6 \mathrm{H}]^{6+}$ ions (Figure 3A). As was determined by tandem MS, glycopeptides differed in the number of hexoses attached to the peptide moiety, which was reflected by a mass difference of $162 \mathrm{Da}$. As an example, the fragmentation spectrum of $\mathrm{m} / z$ 1165.4 $[\mathrm{M}+5 \mathrm{H}]^{5+}$ is shown in Figure 3B. The peptide species is identified as $\mathrm{T}_{99}$ ATVETPSSAASQTAVSQAPASQAPTSQAPATQTPAAPQTDTQTANTQLYVK 150 and was found to carry four hexoses. The $y$ ions as well as the $b_{6}$ ion confirm the identity of these glycopeptides. While most fragment ions including all y ions were observed without the hexoses being attached, the $\mathrm{b}_{19}$ cleavage product was registered without hexoses $(m / z 1788.8)$, with 1 hexose $(m / z$ 1950.8), and with 2 hexoses $(\mathrm{m} / z 2112.8)$, indicating that at least part of the hexoses is linked to the $\mathrm{N}$-terminal portion of this peptide fragment. These data demonstrate that the glycosylation on Msp1 varies from two to five hexoses linked to $\mathrm{T}_{99} \mathrm{~K}_{150}$.

Since the very large tryptic peptides of Msp $1\left(\mathrm{~F}_{204} \mathrm{R}_{378}\right.$, MW15931.57 and $\mathrm{G}_{403} \mathrm{~K}_{481}$, MW 8257.93) could not be detected by MS, they were first digested by proteinase $\mathrm{K}$ and then further subjected to analysis for glycosylation. However, because proteinase $\mathrm{K}$ treatment is known to often result in glycopeptides made up of small peptide moieties (up to 10 amino acid residues) [21] that show no or insufficient retention in reverse phase LC, further analysis was instead performed by graphitized carbon-LC-ion trap-MS/MS. As a result, a group of glycopeptides could be registered that were substituted with one or two hexose residues. As an example, the fragmentation of peptide $\mathrm{T}_{101}$ VETPSSA $_{108}$ substituted with 2 hexose residues is shown in Figure 4. A glycosylated $y_{4}$ fragment ion containing two hexose residues $(\mathrm{m} / \mathrm{z}$ 685.4) allows the assignment of the hexoses to the $\mathrm{S}_{106}-\mathrm{S}_{107}$ dipeptide. The other glycopeptides $\mathrm{T}_{104} \mathrm{PSSA}_{108}, \mathrm{~T}_{101}$ VETPSSA $_{108}$ and $\mathrm{T}_{101}$ VETPSSAA $_{109}$ or $\mathrm{A}_{100}$ TVETPSSA $_{108}$ with one or two hexose residues also covered the same $\mathrm{S}_{106}-\mathrm{S}_{107}$ dipeptide. No glycopeptides were registered covering parts of the large tryptic peptides of $\mathrm{F}_{204} \mathrm{R}_{378}$ and $\mathrm{G}_{403} \mathrm{~K}_{481}$.

Table 2 Sequence coverage of Msp1.Tryptic peptides were registered by RP-LC-ion trap-MS/MS. Filled circles indicate hexoses

\begin{tabular}{|c|c|c|c|}
\hline (Glyco)peptide & Registered signal $(m / z)$ & Calculated mass/determined mass & Mascot score \\
\hline $\mathrm{S}_{33} \mathrm{~K}_{40}$ & Not detected & $841.42 /-$ & \\
\hline $\mathrm{S}_{41} \mathrm{~K}_{56}$ & $595.48[\mathrm{M}+3 \mathrm{H}]^{3+}$ & $1783.41 / 1783.44$ & 60 \\
\hline$R_{57}$ & Not detected & $174.11 /-$ & \\
\hline $\mathrm{Y}_{58} \mathrm{~K}_{81}$ & $720.90[\mathrm{M}+2 \mathrm{H}]^{2+}$ & $1439.78 / 1439.80$ & 90 \\
\hline $\mathrm{T}_{71} \mathrm{~K}_{81}$ & $641.78[\mathrm{M}+2 \mathrm{H}]^{2+}$ & $1281.54 / 1281.56$ & 68 \\
\hline$V_{82} K_{98}$ & $639.34[\mathrm{M}+3 \mathrm{H}]^{3+}$ & 1914.99/1915.02 & 46 \\
\hline $\mathrm{T}_{99} \mathrm{~K}_{150}$ & Not detected & $5170.51 /-$ & \\
\hline $\mathrm{T}_{99} \mathrm{~K}_{150} \bullet \bullet$ & $\begin{array}{l}1374.56[\mathrm{M}+4 \mathrm{H}]^{4+} \\
1099.81[\mathrm{M}+5 \mathrm{H}]^{5+} \\
916.81[\mathrm{M}+6 \mathrm{H}]^{6+}\end{array}$ & $5494.62 / 5494.35$ & Manually assigned \\
\hline $\mathrm{T}_{99} \mathrm{~K}_{150} \bullet \bullet \bullet$ & $\begin{array}{l}\left.1415.06[\mathrm{M}+4 \mathrm{H}]^{4+}\right]^{+} \\
1132.31[\mathrm{M}+5 \mathrm{H}]^{5+} \\
943.75[\mathrm{M}+6 \mathrm{H}]^{6+}\end{array}$ & $5656.67 / 5656.43$ & Manually assigned \\
\hline$T_{99} K_{150} \bullet \bullet \bullet \bullet$ & $\begin{array}{l}1455.55[\mathrm{M}+4 \mathrm{H}]^{4+} \\
1164.69[\mathrm{M}+5 \mathrm{H}]^{5+} \\
970.75[\mathrm{M}+6 \mathrm{H}]^{6}\end{array}$ & $5818.72 / 5818.38$ & Manually assigned \\
\hline $\mathrm{T}_{99} \mathrm{~K}_{150} \bullet \bullet \bullet \bullet$ & $\begin{array}{l}1496.25[\mathrm{M}+4 \mathrm{H}]^{4+} \\
1197.13[\mathrm{M}+5 \mathrm{H}]^{5+} \\
997.88[\mathrm{M}+6 \mathrm{H}]^{6+}\end{array}$ & $5980.77 / 5980.98$ & Manually assigned \\
\hline $\mathrm{N}_{151} \mathrm{R}_{193}$ & $1168.50[\mathrm{M}+4 \mathrm{H}]^{4+}$ & $4669.25 / 4669.0$ & Manually assigned \\
\hline $\mathrm{L}_{194} \mathrm{R}_{203}$ & $509.24[\mathrm{M}+2 \mathrm{H}]^{2+}$ & $1016.46 / 1016.48$ & 49 \\
\hline$F_{204} R_{378}$ & Not detected & 15931.57/- & \\
\hline $\mathrm{Q}_{379} \mathrm{~K}_{381}$ & Not detected & $345.20 /-$ & \\
\hline $\mathrm{I}_{382} \mathrm{~K}_{402}$ & $752.78[\mathrm{M}+3 \mathrm{H}]^{3+}$ & $2255.32 / 2255.34$ & 92 \\
\hline $\mathrm{G}_{403} \mathrm{~K}_{481}$ & Not detected & $8257.93 /-$ & \\
\hline $\mathrm{Y}_{482} \mathrm{~L}_{498}$ & $989.46[\mathrm{M}+2 \mathrm{H}]^{2+}$ & $1976.90 / 1976.92$ & 90 \\
\hline
\end{tabular}




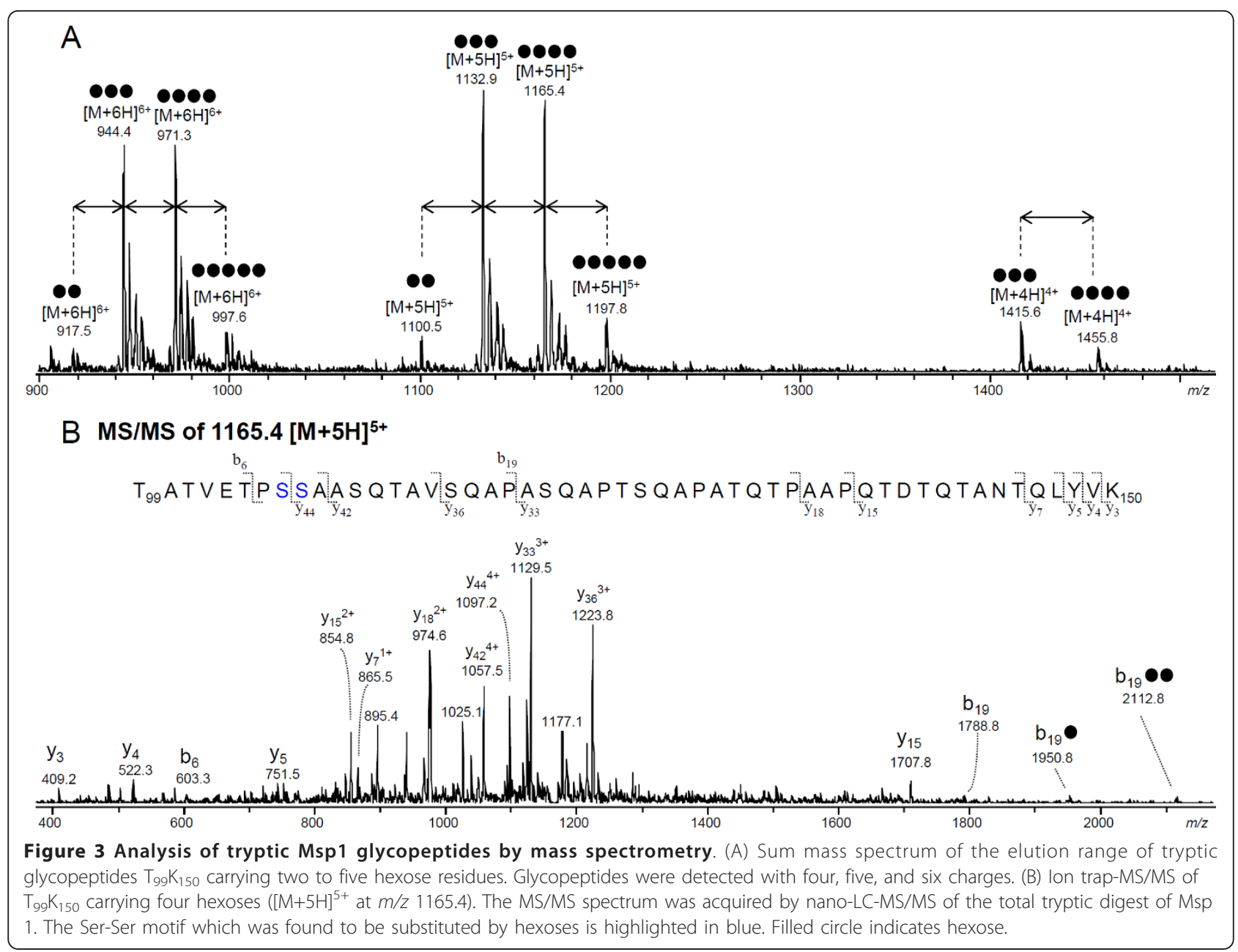

ConA reactivity correlates with presence of the $S_{106}-S_{107}$ dipeptide in $L$. rhamnosus but not in $L$. casei strains Multiple-sequence alignment analysis of the primary structure of Msp1 (p75) from different L. rhamnsosus and $L$. casei strains suggested that the amino acid residues of the $\mathrm{T}_{104} \mathrm{PSSA}_{108}$ fragment covering the $\mathrm{S}_{106}-\mathrm{S}_{107}$ dipeptide in Msp1 of L. rhamnosus strains are replaced with $\mathrm{A}_{104} \mathrm{PEQT}_{108}$ in several L. casei strains [22]. To determine whether this is a factor in ConA reactivity, parallel experiments were performed involving ConA and anti-Msp1 serum blotting (Figure 5A) with spent culture supernatant proteins from different $L$. casei and L. rhamnosus strains that were obtained from our laboratory collection (Table 1). All samples tested from L. rhamnosus and L. casei appeared to exhibit a protein that is recognized by the antiserum raised against recombinant LGG Msp1, although the molecular mass of the Msp1-like proteins in the L. casei strains tested seems to be smaller than Msp1 in the L. rhamnosus strains (Figure 5A). Results from blotting experiments with ConA indicated that only the Msp1 proteins of the L. rhamnosus strains confirmed to have the $S_{106}-S_{107}$ dipeptide (Figure 5B) display the capacity to interact with ConA (Figure 5A).

\section{Msp1 glycosylation is not crucial for Akt activation of LGG Msp1 in Caco-2 cells}

Previously, Msp1 (or p75) was identified by Polk and coworkers as a soluble protein of LGG that can regulate intestinal epithelial cell survival and growth via Akt signaling [16]. Here, we investigated what role the glycan chain of Msp1 plays in Akt activation in the Caco-2 intestinal epithelial cell line. To do this, both purified and TFMS-deglycosylated Msp1 and recombinantly produced Msp1 were used. As shown in Figure 6, no significant difference in Akt activation was found for the glycosylated and non-glycosylated forms. The msp 1 mutant still showed Akt activation, which likely reflects the presence of Msp2, which is a stronger activator of Akt signaling than Msp1 [16]. 

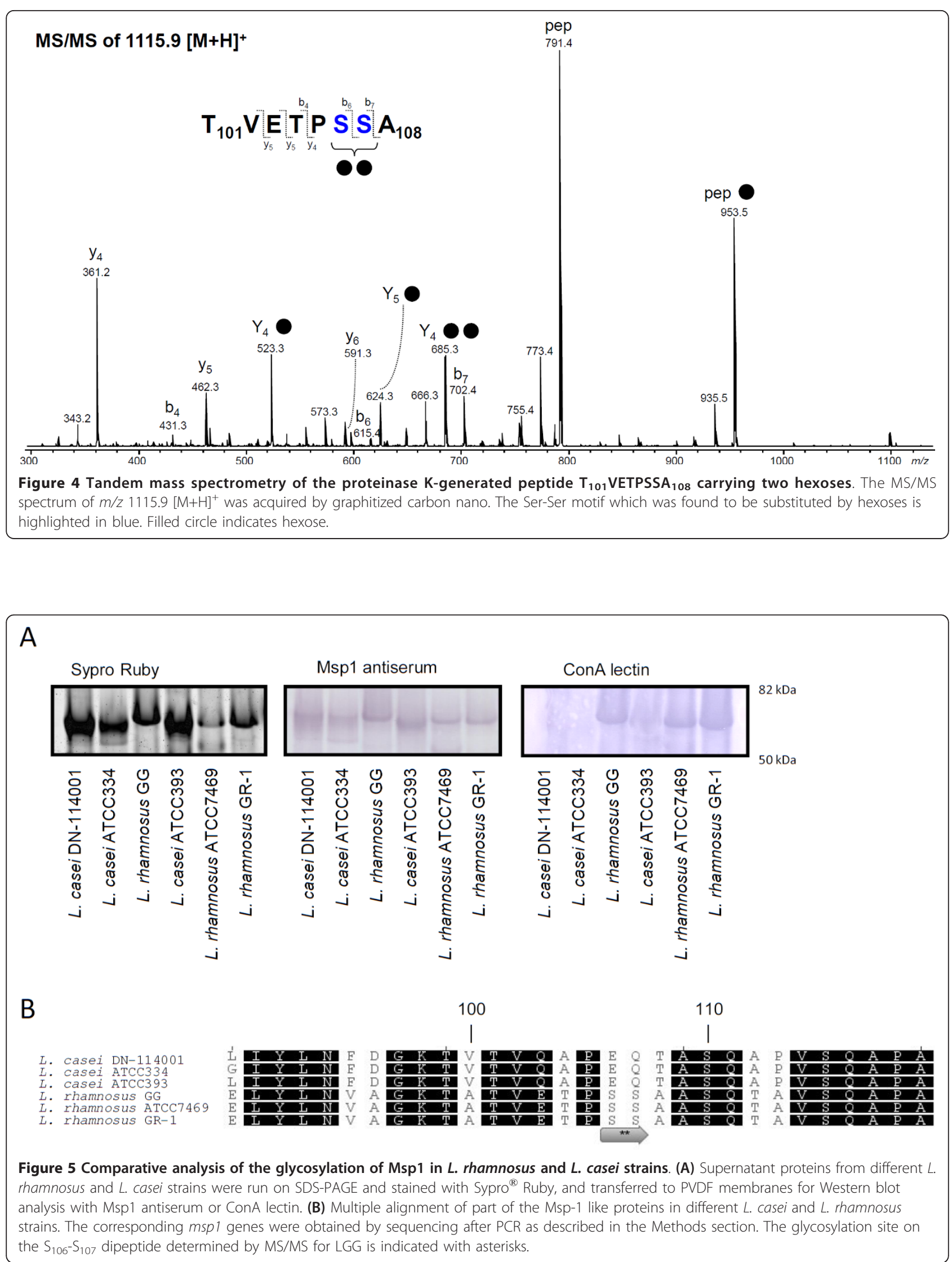

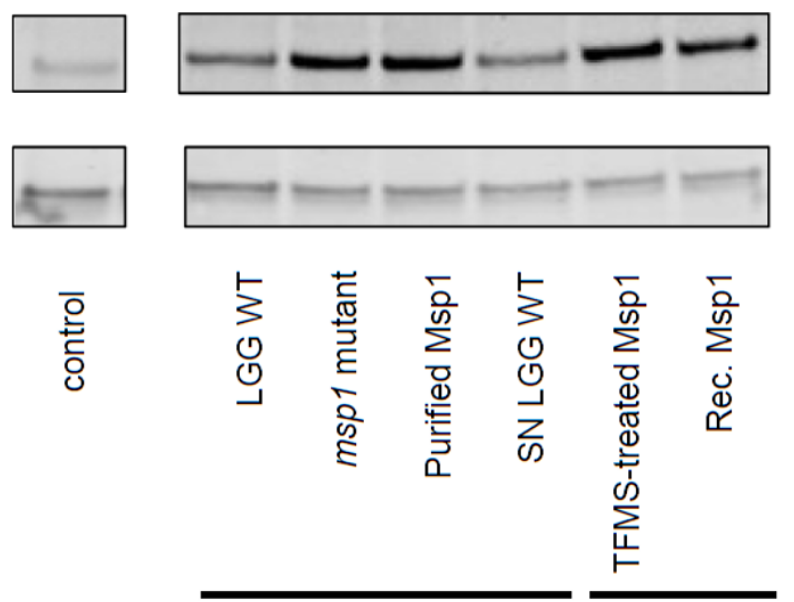

Glycosylated

\section{Non- \\ glycosylated}

Figure 6 Impact of Msp1 glycosylation on Akt activation in intestinal epithelial cells. Caco-2 cells were co-incubated with L. rhamnosus GG wild-type (10 CFU/ml), msp1 mutant CMPG10200 (107 CFU/ml), glycosylated Msp1 after purification with affinity chromatography and ConA sepharose (ca. $100 \mathrm{ng} / \mathrm{ml})$, Msp1 partially purified from spent culture supernatant (SN) (ca. $10 \mathrm{ng} / \mathrm{ml})$, chemically deglycosylated Msp1 after TFMS treatment (ca. $100 \mathrm{ng} / \mathrm{ml}$ ) and recombinantly (rec.) expressed Msp1 after purification from E. coli (ca. $100 \mathrm{ng} / \mathrm{ml}$ ). Subsequent Akt activation was monitored by Western blot analysis of cellular lysates with anti-P-Akt and ant-Akt antibodies. Data are representative for 2 separate experiments.

\section{Msp1 glycosylation is not crucial for peptidoglycan hydrolase activity of Msp1}

Recently, we demonstrated that Msp1 is a peptidoglycan hydrolase with D-glutamyl-L-lysyl endopeptidase activity [17]. Here, we aimed to determine whether glycosylation is required for the peptidoglycan hydrolase activity by comparing the native (glycosylated) and recombinant (non-glycosylated) forms of Msp1. Our zymogram analyses indicated that Msp1 in spent culture supernatant and both purified native and recombinant Msp1 all share the same level of activity (Figure 7). However, the msp1 mutant CMPG10200, which expresses a truncated Msp1 protein that lacks the important catalytic NlpC/ p60 domain, was not active in agreement with our previous results [17].

\section{Msp1 glycosylation is linked with localization in the supernatant}

To ascertain whether a link exists between the cellular location and the glycosylation of Msp1, we isolated proteins from the spent culture supernatant, cell wall, and cytosol, and performed parallel blotting experiments with ConA and anti-Msp1 serum. As our results indicate, although Western blotting with Msp1-specific antiserum confirmed the presence of Msp1 in all cellular fractions, the cytosolic and cell wall fractions showed no significant reactivity with ConA, unlike the spent culture supernatant fraction which did exhibit strong ConA reactivity (Figure 8 ).

\section{Discussion}

In this study, we have reported the presence of an $O$-glycosylated protein in a probiotic Lactobacillus strain. LGG's major secreted protein Msp1, which we renamed from p75

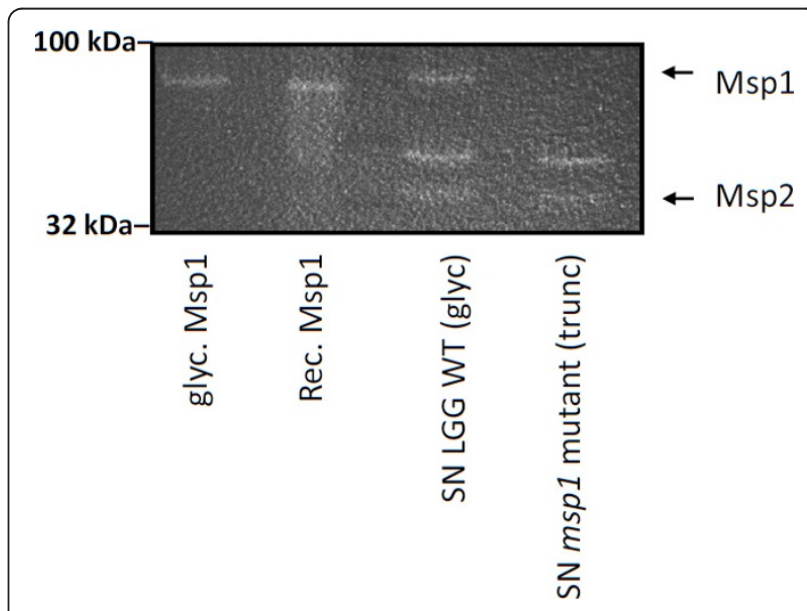

Figure 7 Impact of Msp1 glycosylation on peptidoglycan hydrolase activity. The cell wall hydrolyzing capacity of glycosylated (glyc.) and recombinant (rec.) non-glycosylated Msp1 was determined with msp1 mutant CMPG10200 cells as substrate. Supernatant (SN) samples from LGG wild-type (WT) and the msp1 mutant CMPG10200 were also loaded on the zymogram gels. The gels were incubated overnight at $37^{\circ} \mathrm{C}$ in phosphate buffer containing $1 \mathrm{mM}$ DTT supplemented with the different Msp1 samples and visualized by methylene blue staining as described in materials and methods. 


\section{Msp1 antiserum}
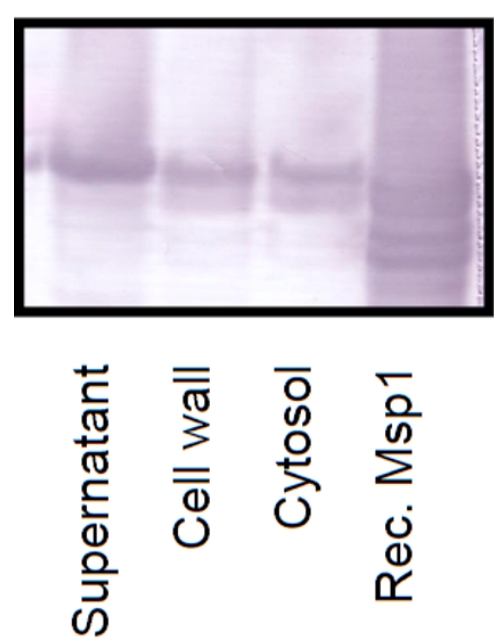

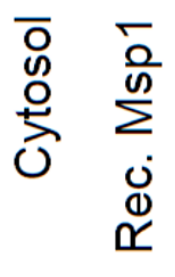

ConA lectin

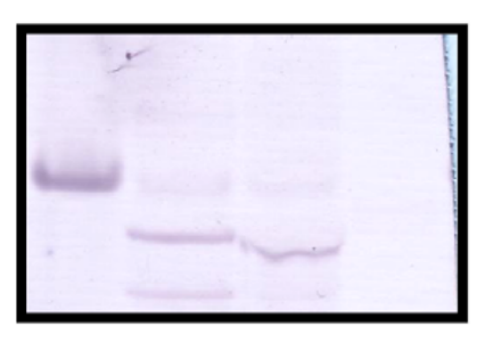

\section{$50 \mathrm{kDa}$}

\section{$100 \mathrm{kDa}$}

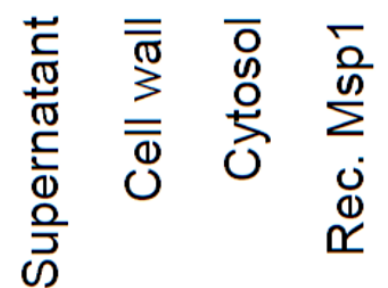

Figure 8 Relationship between Msp1 glycosylation and cellular location. LGG wild-type was grown for $24 \mathrm{~h}$ in AOAC medium and proteins were isolated from spent culture supernatant, the cell wall and cytosol fraction as described in Materials and Methods. Samples were run on SDS-PAGE and blot with Msp1 antiserum or ConA lectin. For comparison, non-glycosylated recombinant Msp1 (rec. Msp1) was included.

[16], has been shown previously to mediate intestinal cell homeostasis through Akt signaling pathways, but also exhibits an interesting aberrant gel migration pattern. To provide evidence for the glycosylation of Msp1, we used a combination of several standard glycosylation detection methods, which include periodate-oxidation, chemical deglycosylation with TFMS, and lectin blotting with ConA, which is specific for mannose or glucose residues. Moreover, we demonstrated that a recombinant form of Msp1, which was produced in a non-glycosylating E. coli host, has a significantly reduced molecular mass and cannot bind to ConA. In addition, we also found that recombinant Msp1 was less stable than the native form. Mass spectrometry experiments confirmed that Msp1 is indeed $\mathrm{O}$-glycosylated and identified a glycopeptide fragment $\left(\mathrm{T}_{101}\right.$ VETPSSA $\left._{108}\right)$ that displays at least two hexose moieties on $\mathrm{S}_{106}-\mathrm{S}_{107}$. These data do not allow distinguishing between the following possibilities: the occurrence of two single hexoses attached to serine residues, or the presence of a disaccharide substituent. In addition, larger glycopeptides species where observed that covered the same $\mathrm{S}_{106^{-}}$ $\mathrm{S}_{107}$ glycosylation site(s) and carried up to 5 hexoses. The obtained fragmentation spectra did not allow the assignment of the hexoses to specific sites. The observed glycopeptides $\mathrm{T}_{99}-\mathrm{K}_{150}$ are rich in serine and threonine residues, which both represent potential hexose attachment sites. Although some y ions representing only the peptide backbone have been detected in the MS/MS spectra of these glycopeptides, the existence of di-, tri-, tetra- or pentahexosyl units attached to Msp 1 remains speculative since no corresponding glycan oxonium ions were observed (e.g. no $\left[\text { hexose }{ }_{2}+\mathrm{H}\right]^{+}$signal at $m / z 325$ ).
However, based on the fragmentation spectrum of the tryptic glycopeptides, the occurrence of such oligosaccharide moieties cannot be excluded. With regard to the nature of the hexose units, the above-mentioned Con A binding in combination with the binding to GNA from Galanthus nivalis and HHA from Hippeastrum hybrid (mannose specific lectins) indicate these to be mannose residues. Additional research is required to completely characterize the O-glycans and exact glycosylation sites of Msp1.

Interestingly, in the homologous forms of Msp1 in several $L$. casei strains tested, which do not react with ConA, these serine residues are missing, thus underscoring their importance as glycosylation sites in Msp1 of LGG (and other L. rhamnosus strains) and the basis for ConA reactivity. However, this does not exclude the possibility that the Msp1-like proteins of $L$. casei are glycosylated at other sites with other sugars. In fact, preliminary lectin blotting experiments suggest glycosylation of Msp1 in L. casei with galactose or $\mathrm{N}$-acetylgalactosamine residues. Thus, our results are strongly suggestive of a species-specific glycosylation mechanism for Msp1 in different L. rhamnosus bacteria.

Subsequently, we investigated the role of the glycan chain in functions established previously for Msp1 of L. rhamnosus GG, which include the activation of Akt signaling in intestinal epithelial cells [16] and a peptiglycan hydrolase activity [17]. Our results indicate that glycosylation of Msp1 does not appear to be crucial for either of these two functions. The lack of a direct role for the glycosylation of Msp1 in its activation of Akt signaling is not surprising, given that Msp2, as an apparently 
non-glycosylated protein (this study), can also activate Akt in intestinal epithelial cells and at lower concentrations than does Msp1 (p75) [16]. However, this does not exclude a possible modulating role for the Msp1 glycan chains in Akt activation. For instance, these glycan components might still act to shield host cell receptors and, in so doing, possibly cause a reduction in the capacity of Msp1 and IECs to interact, thus modulating the extent of Akt signaling. The finding that the specific ConA-reactive glycosylation of Msp1 is not required for peptidoglycan hydrolase activity is in full agreement with the fact that the L. rhamnosus GG and L. casei BL23 Msp1-like proteins both exhibit identical enzymatic properties $[17,23]$, while the glycosylation site $\mathrm{T}_{101}$ VETPSSA $_{108}$ in $L$. rhamnosus GG Msp1 is replaced with $\mathrm{T}_{101} \mathrm{VQAPEQY}_{108}$ in the Msp1-like protein in L. casei BL23 [22] and the Msp1 proteins of the $L$. case $i$ strains used in our study do not show ConA reactivity.

The protein glycosylation machinery of L. rhamnosus GG is currently unknown. Our data related to the cellular localization of Msp1 in L. rhamnosus GG reveal a possible link between the glycosylation of Msp1 and its release into the surrounding milieu. Furthermore, lectin blotting experiments indicate that other secreted proteins, including the putative cell wall hydrolase encoded by LGG_02225 might be glycosylated, suggesting a more global mechanism (data not shown). This would be in agreement with the fact that there appear to be no neighboring genes of the $m s p 1$ gene that putatively encode for glycosyltransferases, in contrast to dedicated protein glycosylation systems [7]. Our future experiments will include determining the exact glycosylation mechanisms and the role of glycosylation of Msp1 and related proteins in the control of their activity and localization. The function of glycosylation for Msp1 might possibly be similar to that which was reported for the HMW1 protein in Haemophilus influenza, which includes the protection against premature degradation and the tethering of protein to the cell surface [24]. In addition, various specific C-type lectin receptors of the innate immune system, such as the dendritic cell-specific intercellular adhesion molecule-3-grabbing nonintegrin DC-SIGN $[10,25]$, show a sugar specificity that overlaps with ConA. Future experiments are also aimed at elucidating the role of Msp1 glycosylation in innate immune signaling.

\section{Conclusions}

In this study we have provided convincing evidence that Msp1 (p75) of the probiotic L. rhamnosus GG is O-glycosylated with ConA-reactive sugars at the serine residues in $\mathrm{T}_{101}$ VETPSSA $_{108}$ once released into the external surroundings. Further studies are now required to determine the exact glycan chain, mechanism and functional importance of glycosylation in Msp1. Nonetheless, the first identification of a glycosylation site in a probiotic-related protein provides interesting opportunities in a safe and food grade bacterium for glyco-engineering purposes such as targeting specific immune cells or enhancing the stability.

\section{Methods}

\section{Bacterial strains and culture conditions}

Lactobacilli (Table 1) were grown at $37^{\circ} \mathrm{C}$ in MRS medium (Difco) or in Lactobacilli AOAC medium (Difco) in non-shaking conditions. CMPG10200 was grown in the presence of $5 \mu \mathrm{g} / \mathrm{ml}$ erythromycin for stable maintenance of the integrative plasmid. In addition, Escherichia coli strains TOP10 [F-mcrA $\Delta$ (mrr-hsdRMS-mcrBC) F80lacZ $\triangle$ M15 $\triangle$ lacX74 recA1 araD139 $\Delta$ (ara-leu)7697 galU galK rpsL (StrR) endA1 nupG] and BL21(DE3)/ pLysS [F- ompT hsdSB(rB-mB-) gal dcm (DE3) pLysS $(C a m R)]$ were used for plasmid preparation and protein expression, respectively. E. coli was routinely grown in Luria-Bertani (LB) medium at $37^{\circ} \mathrm{C}$ with agitation and was supplemented with $50 \mu \mathrm{g} / \mathrm{ml}$ kanamycin when required.

\section{Molecular cloning}

Standard DNA protocols were used for molecular cloning and related procedures as described previously [18]. Sequencing of the $m s p 1$ gene from different $L$. rhamnosus and $L$. casei strains (Table 1 ) was performed on PCR products obtained by colony PCR with primers Pro-0997 (5'ATGAATTCACAGGGACGGTCAGTTACAAATCC3', EcoRI site underlined) and Pro-0998 (5'-ATGA ATTCGTTGTTCGGCAATGGCAATCACTG-3', EcoRI site underlined) for L. rhamnosus and Pro-0679 (5'AGAaAgTATTGTCAgTAACGGCAGG-3') and Pro0680 (5'-TTGGCAAGCCGATACCATGTTTCAC-3') for L. casei strains by Macrolon (The Netherlands). These DNA sequences were translated to amino acid sequence and a multiple alignment around the $\mathrm{S}_{106}-\mathrm{S}_{107}$ dipeptide of LGG was constructed using the Geneious Pro $^{\mathrm{TM}}$ software.

\section{Production of purified recombinant Msp1 protein}

The coding sequence for $m s p 1$ (LGG_00324) not including the sequence for the $\mathrm{N}$-terminal signal peptide was amplified by PCR from LGG genomic DNA by means of two flanking 5'- and 3'-end oligoprimers, one with an EcoRI restriction site (5' - TACCGTTTCGAATTCGACAGGGACGGTC-3', EcoRI site is underlined]) and another with an XhoI restriction site (5'- GATCATTAAGCCTCGAGTGACGGGCGAAC-3', XhoI site is underlined) (Oligomer, Finland). The EcoRI- and XhoI-digested PCR fragment was ligated into the pET28b+ expression vector (Novagen) and the resulting recombinant plasmid (pKTH5316) then propagated in the E. coli strain BL21 (DE3)/pLysS for cytosolic production of C-terminal 
hexahistidine-tagged protein. Recombinant Msp1 (48.4 $\mathrm{kDa}$ ) also consists of an additional seven $\mathrm{N}$-terminal- and two C-terminal-located amino acids, all of which originate from the coding sequence of the expression vector. Recombinant Msp1 production was carried out as described previously [17]. Briefly, E. coli cells with pKTH5316 were cultivated at $37^{\circ} \mathrm{C}$ in LB-kanamycin $(50 \mu \mathrm{g} / \mathrm{ml})$ broth, and at the mid-log phase they were then induced by $1 \mathrm{mM}$ isopropyl $\beta$-D-1-thiogalactopyranoside (IPTG) and grown for another $3 \mathrm{~h}$ to allow the accumulation of recombinant Msp1. After cells were pelleted by centrifugation, they were sonicated in lysis buffer $(50 \mathrm{mM}$ $\mathrm{NaH}_{2} \mathrm{PO}_{4}$ [pH 8.0], $300 \mathrm{mM} \mathrm{NaCl}, 10 \mathrm{mM}$ imidazole) and the broken cell suspension that resulted was then clarified by centrifugation and membrane-filtering $(0.45-\mu \mathrm{m}$ poresize). The clarified suspension was added to a nickel nitrilotriacetic acid (Ni-NTA) agarose (Qiagen) column and, following rinsing with wash buffer $\left(50 \mathrm{mM} \mathrm{NaH}_{2} \mathrm{PO}_{4}[\mathrm{pH}\right.$ 8.0 ], $300 \mathrm{mM} \mathrm{NaCl}, 20 \mathrm{mM}$ imidazole), recombinant Msp1 was recovered with elution buffer $(50 \mathrm{mM}$ $\mathrm{NaH}_{2} \mathrm{PO}_{4}$ [pH 8.0], $300 \mathrm{mM} \mathrm{NaCl}, 250 \mathrm{mM}$ imidazole). Elution buffer was exchanged to $10 \mathrm{mM}$ Tris- $\mathrm{HCl}(\mathrm{pH}$ 8.0) with a Bio-Rad EconoPac 10 DG desalting column and purified Msp1 was then concentrated using a $30-\mathrm{kDa}$ Microsep filter (Pall Life Sciences).

\section{Production of anti-Msp1 serum}

Polyclonal antiserum was raised against purified recombinant Msp1 in rabbit as described previously [17]. In brief, a 1:1 mixture of $400 \mu \mathrm{g}$ Msp1 and Freund's complete adjuvant (1-ml volume) was first administered subcutaneously and then followed by additional $1 \mathrm{ml}$ booster injections $(200 \mu \mathrm{g}$ Msp1 and Freund's incomplete adjuvant as a1:1 mix) every 3 weeks for a total of 9 weeks. Fourteen days after the final booster injection, blood was recovered for antiserum preparation as described elsewhere [26].

\section{Western blot}

For Western blot experiments, equivalent amounts, determined by a bicinchoninic acid (BCA) assay, of protein were separated by SDS-PAGE and subsequently electroblotted onto polyvinyldifluoride (PVDF) membrane. The PVDF sheets were blocked with $3 \%$ bovine serum albumine (BSA) in TBS $(20 \mathrm{mM}$ Tris- $\mathrm{HCl}, 500 \mathrm{mM}$ $\mathrm{NaCl}, \mathrm{pH} 7.5$ ) and incubated at room temperature with Msp1 antiserum (1:7500 to 1:15000) for $1 \mathrm{~h}$. After several washings with TBS, blots were incubated for $1 \mathrm{~h}$ with goat anti-rabbit antibodies conjugated with alkaline phosphatase (Sigma) at a dilution of 1:1000. Detection was performed with nitro blue tetrazolium and bromo-chloro indolyl phosphate as substrate and the blue coloring reaction was monitored.

\section{Isolation of different protein fractions from LGG}

(1) supernatant. LGG bacteria were grown for $24 \mathrm{~h}$ in AOAC-medium. After centrifugation (6000 g, $20 \mathrm{~min})$, proteins were precipitated from supernatant by incubation at $4^{\circ} \mathrm{C}$ for $30 \mathrm{~min}$ in the presence of trichloro acetic acid (20\% final concentration). After centrifugation (9000 g, $20 \mathrm{~min}$ ), precipitated proteins were washed twice with cold acetone. Pellet was air-dried and proteins were resuspended in lysis buffer ( $2 \mathrm{M}$ thio-urea, $7 \mathrm{M}$ urea, $4 \%$ CHAPS, 2\% DTT). (2) cell wall. After centrifugation (6000 g, $20 \mathrm{~min}$ ) and washing with PBS, bacteria were sonicated in PBS buffer (Branson sonifier) until lysis was observed (several minutes at $10 \%$ power). Lysate was cleared by centrifugation ( 3 times at $4000 \mathrm{~g}$ ). Cell wall proteins were precipitated by ultracentrifugation $(22000 \mathrm{~g}$ for $45 \mathrm{~min}$ ). Pellet was washed 3 times with $50 \mathrm{mM}$ Tris pH8, $500 \mathrm{mM} \mathrm{NaCl}$ and dissolved in a small volume PBS. (3) cytosol. After centrifugation (6000 g, $20 \mathrm{~min})$, the pellet was washed $2 \times$ with $0.9 \% \mathrm{NaCl}$. Subsequently, the pellet was dissolved in $1 \mathrm{ml} 100 \mathrm{mM}$ Tris, 1\% SDS, pH 9.5 and sonicated for $3 \mathrm{~min}$ (0.5" on, 1.5" off) with a Branson sonifier. Subsequently, cell debris was removed by centrifugation and proteins were precipitated with TCA precipitation, two times washed with ice-cold $100 \%$ acetone, air-dried and then dissolved in PBS.

\section{Purification of the L. rhamnosus GG Msp1 protein}

The $\mathrm{p} 75 / \mathrm{Msp} 1$ protein was partially purified by cationic exchange as described previously [16]. Hereto, L. rhamnosus GG was grown for $24 \mathrm{~h}$ in AOAC medium, after which spent culture medium was collected (6000 g, $20 \mathrm{~min}$ ). The culture supernatant was then loaded onto a SP Sepharose HighPerfomance column (GE Healthcare), equilibrated with $60 \mathrm{mM}$ lactate buffer $\mathrm{pH}$ 4.0. Bound proteins were eluted using lactate buffer containing sequential $\mathrm{NaCl}$ concentrations (100-1000 mM). Fractions positive for the presence of Msp1 were identified using SDS-PAGE and spin concentrated using Vivaspin filters with MW cut off 10.000 (Sartorius Stedim biotech GmbH, Germany). For the MS/MS experiments, Hi-trap ConA 4B prepacked columns (GE Healthcare) were used according to manufacturer's instructions to further purify positive fractions.

\section{Characterization of glycan nature of the p75/Msp1 protein}

(i) ProQ Emerald glycoprotein stain. Samples were loaded onto the wells of the SDS-containing gel after adding buffer and reducing agent according to manufacturer's instructions from the Pro-Q Emerald 488 Glycopotein Gel and Blot stain kit (Molecular Probes, Invitrogen). (ii) Treatment with TFMS. Msp1 was chemically deglycosylated by the TFMS method as described before [27] at $-20^{\circ} \mathrm{C}$ for $30 \mathrm{~min}$. After 
treatment, the proteins were extensively dialyzed and then analyzed by SDS-PAGE. (iii) Lectin blotting. The proteins were electroblotted onto PVDF membrane similar as for Western blot. After blocking, the PVDF sheets were incubated at room temperature with lectins conjugated with biotin (biotinylated ConA, WGA or Ulex europaeus, Sigma-Aldrich or GNA, HHA, MAA

SNA-I purified and biotinylated according to [20] for $1 \mathrm{~h}$ at final concentrations of $0.25 \mu \mathrm{g} / \mathrm{ml}$ in the presence of $1 \mathrm{mM} \mathrm{Mg}^{2+}$ and $1 \mathrm{mM} \mathrm{Ca}^{2+}$ ions. After washing, blots were incubated for $1 \mathrm{~h}$ with streptavidin conjugated with alkaline phosphatase (Roche) at a dilution of 1:1000. Detection was performed as described for Western blotting.

\section{MS determinations}

The LGG Msp1 protein purified by cation exchange chromatography was applied to SDS-PAGE using $\mathrm{Nu}$-Page 4-12\% gradient Bis-Tris (Invitrogen) gels. The excised gel pieces containing Msp1 were reduced, alkylated and digested with trypsin (Promega), as previously described [28] or with Proteinase K (from T. album; Sigma-Aldrich) [21]. After digestion, (glyco-)peptides were collected using two rounds of extraction with $20 \mu \mathrm{l}$ of $0.1 \%$ trifluoroacetic acid and stored at $-20^{\circ} \mathrm{C}$ prior to analysis by mass spectrometry. The total tryptic digest of Msp1 was applied to a reverse phase column (PepMap, $3 \mu \mathrm{m}, 75 \mu \mathrm{m} \cdot \mathrm{x} 100 \mathrm{~mm}$; Dionex/Thermo Fisher, Waltham, MA) using an Ultimate 3000 nano-LC system (Dionex/Thermo Fisher). The column was equilibrated at RT with eluent A $(0.1 \%$ formic acid in water) at a flow rate of $300 \mathrm{nl} / \mathrm{min}$. After injection of the sample a linear gradient was applied (15 min 25\% eluent B (95\% acetonitrile), 25 min 70\% B, 30 min 70\% B). The eluate was monitored by absorption at $215 \mathrm{~nm}$. The LC column was coupled to an Esquire HCT-Ultra ESI-ion trap-MS (Bruker Daltonics, Bremen, Germany) equipped with an online nanospray source operated in the positive ion mode. For electrospray (1100-1250 V), electropolished, stainless steel LC-MS emitters $(150 \mu \mathrm{m}$ OD, $30 \mu \mathrm{m}$ ID) from Proxeon A/S (Odense, Denmark) were used. The solvent was evaporated at $170^{\circ} \mathrm{C}$ employing a nitrogen stream of $6 \mathrm{l} / \mathrm{min}$. When operated in the auto MS/MS mode, monitoring ions from $\mathrm{m} / z 500$ to 1600 , each MS scan was followed by the acquisition of MS/MS spectra of up to five of the most abundant ions in the MS spectrum.

The digest generated by Proteinase K was separated using an Ultimate 3000 nano-LC system (Dionex/ Thermo Fisher) equipped with a graphitized carbon trap column (Hypercarb, $5 \mu \mathrm{m}, 170 \mu \mathrm{m} \times 10 \mathrm{~mm}$; Thermo Scientific) and nano column $(75 \mu \mathrm{m} \times 100 \mathrm{~mm})$ packed by Grom Analytik (Rottenburg, Germany). The column was equilibrated at RT with eluent A ( $0.1 \%$ formic acid in water) at a flow rate of $400 \mathrm{nl} / \mathrm{min}$. After injection of the sample a linear gradient was applied (15 min, 25\% eluent
B (95\% acetonitrile); 25 min, 70\% B; 30 min, 70\% B). The eluate was monitored by absorption at $215 \mathrm{~nm}$. Eluates were analyzed by ESI-ion trap-MS as described above. The ions were monitored from $\mathrm{m} / z 300$ to $\mathrm{m} / z 1500$ in the MS mode. The MS/MS spectra were analyzed with Data Analysis (Bruker Daltonics), converted to MGF files and searched against NCBI database, with search limitation "bacteria" using the MASCOT search algorithm. Carbamidomethylation of cysteines was set as a fixed modification and oxidized methionines were set as a variable modification. Trypsin was specified as the proteolytic enzyme and missed cleavages were not allowed. The mass tolerance of the precursor ion was set to $2 \mathrm{Da}$ and that of the fragment ions was set to $0.5 \mathrm{Da}$. In addition, MS/MS spectra were used for manual interpretation and de novo sequencing.

\section{Activation of Akt in Caco-2 cells}

Caco-2 cells were cultured as described before [15]. $24 \mathrm{~h}$ before the experiments, the Caco- 2 cells were deprived of FBS. LGG wild-type was grown overnight in AOAC medium, centrifuged at $4000 \times \mathrm{g}$ and $4^{\circ} \mathrm{C}$ for $10 \mathrm{~min}$, and washed with cold PBS. Caco-2 cells were incubated with $1.5 \mathrm{ml}$ of DMEM without FBS containing either $1 \times 10^{7}$ CFU/ml LGG wild-type or msp1 mutant CMPG10200, $100 \mathrm{ng} / \mathrm{ml}$ wild-type, recombinant or TFMS-treated Msp1. DMEM without FBS was used as a negative control. After $16 \mathrm{~h}$ incubation at $37^{\circ} \mathrm{C}$, cell lysates were made with HEPES-lysis buffer containing $25 \mathrm{mM}$ HEPES pH 7.5, $0.3 \mathrm{M} \mathrm{NaCl}, 1.5 \mathrm{mM} \mathrm{MgCl}_{2}, 20 \mathrm{mM} \beta$-glycerol-phosphate, 2 mM EDTA, 2 mM EGTA, 1 mM DTT, 1\% (v/v) Triton $\mathrm{X}-100,10 \%(\mathrm{v} / \mathrm{v})$ glycerol, $10 \mu \mathrm{g} / \mu \mathrm{l}$ leupeptin, $5 \mu \mathrm{g} / \mu \mathrm{l}$ aprotinin, $1 \mathrm{mM}$ PMSF, $1 \mathrm{mM} \mathrm{Na} \mathrm{VO}_{4}$ and $50 \mathrm{mM} \mathrm{NaF}$. Protein concentration was determined using BCA assay (Perbio, Thermo Fisher Scientific). Samples with loading buffer were prepared and processed on the CriterionTM system (Bio-Rad Laboratories, Hercules, CA, USA) on a 4-12\% Bis-TRIS gel (Biorad) and Protran $2 \mu \mathrm{m}$-pored nitrocellulose membrane (Perkin-Elmer, Wellesley, MA, USA). Membranes were blocked for $1 \mathrm{~h}$ at room temperature in Tris-buffered saline containing $0.1 \%$ Tween- 20 and $5 \%$ BSA. The membrane was incubated overnight at $4{ }^{\circ} \mathrm{C}$ with the primary antibody diluted in 5\% BSA in $1 \times$ TBS plus $0.1 \%$ Tween 20 , then washed 3 times with TBS plus $0.1 \%$ Tween 20 , followed by incubation with the second polyclonal antibody for $2 \mathrm{~h}$ at $4{ }^{\circ} \mathrm{C}$. Antibodies against phospho-AKT (Ser473) and total AKT were obtained from Cell Signaling Technology (Beverly, MA).

\section{Zymogram analysis}

The cell wall hydrolyzing activity was investigated by zymogram analysis as described previously by Lepeuple et al. (14). SDS-PAGE was performed with $10 \%(\mathrm{w} / \mathrm{v})$ polyacrylamide separating gels (NuPage, Invitrogen). 
Autoclaved LGG cells treated with 10\% TCA were added to the gels as enzyme substrates and the gels were loaded with 10 to $20 \mu \mathrm{g}$ of protein samples. After sample migration, the gels were washed for $30 \mathrm{~min}$ in deionized $\mathrm{H}_{2} \mathrm{O}$ at room temperature and then incubated in a phosphate buffer, $\mathrm{pH}$ 6.2, $1 \mathrm{mM}$ dithiothreitol (DTT) containing $0.1 \%(\mathrm{v} / \mathrm{v})$ Triton X-100, overnight at $37^{\circ} \mathrm{C}$. The gels were subsequently washed for $30 \mathrm{~min}$ in deionized $\mathrm{H}_{2} \mathrm{O}$, then stained with $0.1 \%$ methylene blue in $0.01 \%(\mathrm{w} / \mathrm{v}) \mathrm{KOH}$ for $2 \mathrm{~h}$ at room temperature and destained in deionized $\mathrm{H}_{2} \mathrm{O}$.

\section{List of abbreviations}

DMEM: Dulbecco's Modified Eagle Medium; ConA: concanavalin A; CW-PS: cell wall polysaccharides; EPS: exopolysaccharides; ESI: electrospray ionization; GNA: Galanthus nivalis lectin; HHA: Hippeastrum hybrid lectin; IEC: intestinal epithelial cell; LC: liquid chromatography; LGG: Lactobacillus rhamnosus GG; MAA: Maackia amurensis lectin; MS: mass spectrometry; Msp: major secreted protein; RP: reverse phase; SN: supernatant; SNA-I: Sambucus nigra lectin I; TFMS: trifluoromethanesulfonic acid; WGA: wheat germ agglutinin

\section{Acknowledgements}

At the time of experiments, S.L. was a postdoctoral researcher of the fund for scientific research (FWO) of Flanders, Belgium and I.J.J.C. held a PhD grant of the Institute for the Promotion of Innovation through Science and Technology in Flanders (IWT-Vlaanderen). Funding of this project at the K.U. Leuven was in part through the Fund for Scientific Research, Flanders (FWO) (Grant G.0236.07) and in part through TEKES (Finnish Funding Agency for Technology and Innovation) (Grant 201/08). Work performed at the University of Helsinki was funded by an Academy of Finland research grant (118165) and was part of the Center of Excellence in Microbial Food Safety Research (MiFoSa) and the Research Program on Nutrition, Foods, and Health (ELVIRA).

We thank Ilkka Palva (University of Helsinki) for his stimulating scientific insight and inspiration and Esa Pohjolainen, Katariina Kojo, and Marko Sutinen at the University of Helsinki for their excellent technical expertise in purifying recombinant Msp1 protein.

\section{Author details}

${ }^{1}$ Centre of Microbial and Plant Genetics, K.U.Leuven, Kasteelpark Arenberg 20, box 2460, B-3001 Leuven, Belgium. ${ }^{2}$ Department of Bioscience Engineering, University of Antwerp, Groenenborgerlaan 171, B-2020 Antwerp, Belgium. 'Biomolecular Mass Spectrometry Unit, Department of Parasitology, Leiden University Medical Center, Leiden, The Netherlands. ${ }^{4}$ Cell Death Research \& Therapy laboratory, Department Molecular and Cell Biology, Faculty of Medicine, K.U.Leuven, Herestraat 49, box 901, B-3000, Belgium. ${ }^{5}$ Department of Veterinary Biosciences, University of Helsinki, P.O. Box 66 FIN-00014, Helsinki, Finland. ${ }^{6}$ Department of Molecular Biotechnology, Ghent University, Ghent, Belgium.

\section{Authors' contributions}

SL designed and performed part of the experiments, analyzed the data and wrote the paper. IJJC constructed the msp1 mutant, carried out part of the zymogram analysis and participated in the analysis of the data and editing of the paper. CIAB performed the MS analyses and participated in the analysis of the data and editing of the paper. GS was responsible for the proteomic experiments in this study. TLAV carried out part of the molecular DNA work. HLPT participated in the glycoproteomic analyses. IVO was responsible for the expression of recombinant Msp1 protein and production of anti-Msp1 serum and also participated in the writing of the paper. KN and PA participated in the Akt signaling analysis. EJMVD provided some lectins used in this study and useful comments for glycoprotein detection. WMdV, AP and AMD participated in the design of the study. MW, SCJDK and JV participated in the design and coordination of the experiments, analysis of the data and writing of the manuscript. All authors read and approved the final manuscript.

\section{Competing interests}

The authors declare that they have no competing interests.

Received: 26 September 2011 Accepted: 1 February 2012 Published: 1 February 2012

\section{References}

1. Lebeer S, Vanderleyden J, De Keersmaecker S: Genes and molecules of Lactobacillus supporting probiotic action. Microbiol Mol Biol Rev 2008, 72(4):728-764.

2. Remus DM, Kleerebezem M, Bron PA: An intimate tête-à-tête - how probiotic lactobacilli communicate with the host. Eur J Pharmacol 2011, 668(1 Suppl):S33-S42.

3. Reid CW, Fulton KM, Twine SM: Never take candy from a stranger: the role of the bacterial glycome in host-pathogen interactions. Future Microbiol 2010, 5(2):267-288.

4. Upreti RK, Kumar M, Shankar V: Bacterial glycoproteins: Functions, biosynthesis and applications. Proteomics 2003, 3(4):363-379.

5. Schmidt MA, Riley LW, Benz I: Sweet new world: glycoproteins in bacterial pathogens. Trends Microbiol 2003, 11(12):554-561.

6. Hitchen PG, Dell A: Bacterial glycoproteomics. Microbiology 2006, 152(Pt6):1575-1580.

7. Nothaft H, Szymanski CM: Protein glycosylation in bacteria: sweeter than ever. Nat Rev Microbiol 2010, 8(11):765-778.

8. Bermúdez-Humarán LG, Kharrat P, Chatel JM, Langella P: Lactococci and lactobacilli as mucosal delivery vectors for therapeutic proteins and DNA vaccines. Microb Cell Fact 2011, 10(1 Suppl):S4.

9. Solá RJ, Griebenow K: Glycosylation of therapeutic proteins: an effective strategy to optimize efficacy. BioDrugs 2010, 24(1):9-21.

10. Lebeer S, Vanderleyden J, De Keersmaecker S: Host interactions of probiotic bacterial surface molecules: comparison with commensals and pathogens. Nat Rev Microbiol 2010, 8(3):171-184.

11. Wells J: Immunomodulatory mechanisms of lactobacilli. Microb Cell Fact 2011, 10(1 Suppl):S17.

12. Konstantinov SR, Smidt H, de Vos WM, Bruijns SCM, Singh SK, Valence F, Molle D, Lortal S, Altermann E, Klaenhammer TR, van Kooyk Y: S layer protein A of Lactobacillus acidophilus NCFM regulates immature dendritic cell and T cell functions. Proc Natl Acad Sci USA 2008, 105(49):19474-19479.

13. Doron S, Snydman DR, Gorbach SL: Lactobacillus GG: Bacteriology and clinical applications. Gastroenterol Clin North Am 2005, 34(3):483-498.

14. Francius G, Lebeer S, Alsteens D, Wildling L, Gruber HJ, Hols P, De Keersmaecker S, Vanderleyden J, Dufrêne YF: Detection, localization and conformational analysis of single polysaccharide molecules on live bacteria. ACS Nano 2008, 2(9):1921-1929.

15. Lebeer S, Verhoeven TLA, Francius G, Schoofs G, Lambrichts I, Dufrene YF Vanderleyden J, De Keersmaecker SC: Identification of a gene cluster for the biosynthesis of a long galactose-rich exopolysaccharide in Lactobacillus rhamnosus GG and functional analysis of the priming glycosyltransferase. App/ Environ Microbiol 2009, 75(11):3554-3563.

16. Yan F, Cao HW, Cover TL, Whitehead R, Washington MK, Polk DB: Soluble proteins produced by probiotic bacteria regulate intestinal epithelial cell survival and growth. Gastroenterol 2007, 132(2):562-575.

17. Claes IJJ, Schoofs G, Regulski K, Courtin P, Chapot-Chartier MP, Rolain T, Hols P, von Ossowski I, Reunanen J, de Vos WM, Palva A, Vanderleyden J, De Keersmaecker SCJ, Lebeer S: Genetic and biochemical characterization of the cell wall hydrolase activity of the major secreted proteins of Lactobacillus rhamnosus GG. PLoS One 2012, doi: 10.1371/journal. pone.0031588

18. Sambrook J, Fritsch EF, Maniatis T: Molecular cloning: a laboratory manual. NY: Cold Spring Harbor; 1989.

19. Goldstein IJ, Poretz RD: The Lectins: Properties, functions, and applications in biology and medicine. San Diego: Academic Press; 1986.

20. Van Damme EJM, Peumans WJ, Pusztai A, Bardocz S: Handbook of Plant Lectins Properties and Biomedical Applications. West Sussex, England: Wiley; 1998.

21. Zauner G, Koeleman CA, Deelder AM, Wuhrer M: Protein glycosylation analysis by HILIC-LC-MS of Proteinase K-generated N- and Oglycopeptides. J Sep Sci 2010, 33(6-7):903-910. 
22. Bauerl C, Perez-Martinez G, Yan F, Polk DB, Monedero V: Functional Analysis of the p40 and p75 proteins from Lactobacillus casei BL23. J Mol Microbiol Biotechnol 2010, 19(4):231-241.

23. Regulski K, Courtin P, Meyrand M, Claes IJJ, Lebeer S, Vanderleyden J, Hols P, Guillot, Chapot-Chartier MP: Characterization of the major gglutamyl-L-lysyl-endopeptidase identified by a proteomic analysis in Lactobacillus casei BL23. PLoS One 2012, accepted.

24. Grass S, Buscher AZ, Swords WE, Apicella MA, Barenkamp SJ, Ozchlewski N: The Haemophilus influenzae HMW1 adhesin is glycosylated in a process that requires HMW1C and phosphoglucomutase, an enzyme involved in lipooligosaccharide biosynthesis. Mol Microbiol 2003, 48(3):737-751.

25. van Kooyk Y: C-type lectins on dendritic cells: key modulators for the induction of immune responses. Biochem Soc Trans 2008, 36(Pt6):1478-1481.

26. Harlow E, Lane D: Antibodies: a laboratory manual. New York: Cold Laboratory Press, Cold Spring Harbor; 1988.

27. Sojar HT, Bahl OP: Chemical deglycosylation of glycoproteins. Methods Enzymol 1987, 138:341-350

28. Steen H, Pandey A, Andersen JS, Mann M: Analysis of tyrosine phosphorylation sites in signaling molecules by a phosphotyrosinespecific immonium ion scanning method. SCi STKE 2002, 2002(154):116.

29. Lebeer S, De Keersmaecker SCJ, Verhoeven TLA, Fadda AA, Marchal K, Vanderleyden J: Functional analysis of luxS in the probiotic strain Lactobacillus rhamnosus GG reveals a central metabolic role important for growth and biofilm formation. J Bacteriol 2007, 189(3):60-871.

30. Lebeer S, Claes IJJ, Verhoeven TLA, Shen C, Lambrichts I, Ceuppens IL, Vanderleyden J, De Keersmaecker SC: Impact of luxS and suppressor mutations on the gastrointestinal transit of Lactobacillus rhamnosus GG. Appl Environ Microbiol 2008, 74(15):4711-4718.

31. Francius $G$, Alsteens D, Dupres V, Lebeer $S$, De Keersmaecker $S$, Vanderleyden J, Gruber HJ, Dufrêne YF: Stretching polysaccharides on live cells using single molecule force spectroscopy. Nature Prot 2009, 4(6):939-946.

32. Gardiner GE, Heinemann C, Baroja ML, Bruce AW, Beuerman D, Madrenas J, Reid G: Oral administration of the probiotic combination Lactobacillus rhamnosus GR-1 and L. fermentum RC-14 for human intestinal applications. Int Dairy J 2002, 12:191-196.

doi:10.1186/1475-2859-11-15

Cite this article as: Lebeer et al:: The major secreted protein Msp1/p75 is O-glycosylated in Lactobacillus rhamnosus GG. Microbial Cell Factories 2012 11:15

\section{Submit your next manuscript to BioMed Central and take full advantage of:}

- Convenient online submission

- Thorough peer review

- No space constraints or color figure charges

- Immediate publication on acceptance

- Inclusion in PubMed, CAS, Scopus and Google Scholar

- Research which is freely available for redistribution 